Published in final edited form as:

Cochrane Database Syst Rev. ; (1): CD005656. doi:10.1002/14651858.CD005656.pub2.

\title{
Intravitreal steroids for macular edema in diabetes
}

\author{
Donald A Grover ${ }^{1}$, Tianjing $\mathrm{Li}^{2}$, and Colin CW Chong ${ }^{3}$ \\ ${ }^{1}$ Department of Ophthalmology, Strong Memorial Hospital, NY, Rochester, USA \\ ${ }^{2}$ Cochrane Eyes and Vision Group US Project, Baltimore, USA \\ ${ }^{3}$ Department of Ophthalmology and Eye Health, Save Sight Institute, Sydney, Australia
}

\begin{abstract}
Background-Macular edema is secondary to leakage from diseased retinal capillaries and is an important cause of poor central visual acuity in patients with diabetic retinopathy.
\end{abstract}

Objectives-This review evaluated the effectiveness and safety of intraocular steroids in treating diabetic macular edema (DME).

Search methods-We searched CENTRAL, MEDLINE, EMBASE in June 2007, reference lists, Science Citation Index and conference proceedings.

Selection criteria-We included randomized clinical trials (RCTs) evaluating any form of intravitreal steroids for treating DME.

Data collection and analysis-Two authors independently assessed eligibility, methodological quality and extracted data. We performed meta-analyses when appropriate.

Main results-Seven studies, involving 632 DME eyes were included. Four examined the effectiveness of intravitreal triamcinolone acetate injection (IVTA), three examined intravitreal steroids implantation (fluocinolone acetonide implant (FAI) or dexamethasone drug delivery system (DDS)). Two trials were at low risk of bias, one was at median risk of bias, two were at high risk of bias and the remaining two were at unclear risk of bias.

The preponderance of data suggest a beneficial effect from IVTA. Comparing IVTA with controls, the mean difference in visual acuity was $-0.15 \operatorname{LogMAR}(95 \% \mathrm{CI}-0.21$ to -0.09$)$ at 3 months

Contact person Donald A Grover, Department of Ophthalmology, Strong Memorial Hospital, Box 659, 601 Elmwood Avenue, Rochester, NY, 14642, USA, dagrover@ frontiernet.net.

Contributions of authors

Conceiving the review: TL

Designing the review: DG, TL, CCCW

Co-ordinating the review: TL

Undertaking manual searches: TL

Screening search results: DG, TL, CCCW

Organizing retrieval of papers: TL

Screening retrieved papers against inclusion criteria: DG, TL, CCCW

Appraising quality of papers: DG, TL

Extracting data from papers: DG, TL

Writing to authors of papers for additional information: TL

Providing additional data about papers: DG, TL

Obtaining and screening data on unpublished studies: DG, TL

Data management for the review: TL

Entering data into RevMan: TL

Analysis of data: TL

Interpretation of data: DG, TL, CCCW

Writing the review: DG, TL

Performing previous work that was the foundation of current study: DG, CCCW 
(based on three trials), $-0.23 \operatorname{LogMAR}(95 \% \mathrm{CI}-0.33$ to -0.13 ) at 6 months (two trials), -0.29 LogMAR (95\% CI -0.47 to -0.11 ) at 9 months (one trial), and $-0.11 \operatorname{LogMAR}$ (95\% CI -0.20 to -0.03 ) at 24 months (one trial), all in favor of IVTA. The relative risk (RR) for one or more lines improvement in visual acuity was 2.85 (95\% CI 1.59 to 5.10) at 3 months (two trials), 1.25 (95\% CI 0.66 to 2.38) at 6 months (one trial), and 2.17 (95\% CI 1.15 to 4.11 ) at 24 months (one trial), all in favor of IVTA. We did not find evidence for three or more lines improvement in visual acuity. The mean difference in retinal thickness was -131.97 um (95\% CI -169.08 to -94.86$)$ at 3 months (two trials), -135.00 um (95\% CI -194.50 to -75.50$)$ at 6 months (one trial), -133.00 um (95\% CI -199.86 to -66.14 ) at 9 months (one trial), and -59.00 um (95\% CI -103.50 to -14.50$)$ at 24 months (one trial), all in favor of IVTA. The RR for at least one grade macular edema resolution was 5.15 (95\% CI 2.23 to 11.88) at 3 months in favor of IVTA (one trial).

Two trials reported improved clinical outcome when FAI was compared to standard of care. Beneficial effect was also observed in one dexamethasone DDS trial.

Increased intraocular pressure and cataract formation were side effects requiring monitoring and management.

Authors' conclusions-RCTs included in this review suggest that steroids placed inside the eye by either intravitreal injection or surgical implantation may improve visual outcomes in eyes with persistent or refractory DME. Since the studies in our report focused on chronic or refractory DME, the question arises whether intravitreal steroids therapy could be of value in other stages of DME, especially the earlier stages either as standalone therapy or in combination with other therapies, such as laser photocoagulation.

\section{Plain language summary}

\section{Intravitreal steroids for macular edema in people with diabetes}

Macular edema, swelling of the center of the retina (the part of the eye responsible for our sharpest vision), is an important cause of poor vision in patients with diabetes. New forms of therapy are desirable because the current treatment including laser photocoagulation does not control all cases of diabetic macular edema (DME) and because laser therapy may destroy normal retinal tissue. Intraocular steroids in the form of intravitreal triamcinolone acetate injection (IVTA) and surgical implantation of fluocinolone acetonide (FAI) or dexamethasone drug delivery system (DDS) are promising new therapies. This systematic review included seven randomized clinical trials involving 632 eyes from five countries evaluating the effectiveness and safety of intravitreal steroids for treating DME. Two trials were at low risk of bias, one was at median risk of bias, two were at high risk of bias, and the remaining two had an unclear risk of bias. In this systematic review, the preponderance of data suggest a beneficial effect from IVTA. The average improvement in visual acuity was 7.5 letters more (-0.15 LogMAR; 95\% CI -0.21 to -0.09$)$ in the IVTA treated eyes than in those treated with other therapies at three months (based on three trials), 11.5 letters more (-0.23 LogMAR; 95\% CI -0.33 to -0.13 ) at six months (two trials), 14.5 letters more $(-0.29 \operatorname{LogMAR} ; 95 \% \mathrm{CI}-0.47$ to -0.11$)$ at nine months (one trial), and 5.7 letters more $(-0.11$ LogMAR; $95 \% \mathrm{CI}-0.20$ to -0.03$)$ at 24 months (one trial). Improved clinical outcomes were also reported in FAI and dexamethasone DDS trials. Elevation of intraocular pressure and cataract progression occur in both IVTA and implants treated eyes but appear manageable.

\section{Background}

Introduction

Diabetic macular edema (DME) is the result of retinal microvascular changes that present in both type I and type II diabetes mellitus. It is the most common cause of visual loss in type 
II diabetes (Tranos 2004). It can be defined as macular retinal thickening caused by diabetic retinopathy. Since diabetic retinopathy can exist without macular edema the mere presence of diabetic retinopathy does not, by itself, confirm the diagnosis of DME. Other possible causes of macular edema exist and more than one etiology may play a role in the retinal thickening. Diabetic macular edema must, therefore, be distinguished from other possible independent or contributory causes of the macular edema.

Two types of macular edema have been described: focal and diffuse. Focal macular edema derives from individual microaneurysms or small clusters of microaneurysms and dilated capillaries (Cunha-Vaz 1998). Diffuse macular edema is characterized by diffuse leakage from extensive areas of the posterior retinal capillary bed and a generalized breakdown of the inner blood-retinal barrier (Aroca 2004). The excessive vascular permeability, resulting in the leakage of fluid, lipoproteins, and other plasma constituents into the retina, leads to thickening of the retina (Verma 2004).

\section{Epidemiology}

The published data regarding the epidemiology of DME are dominated by a few large studies. The Wisconsin Epidemiologic Study of Diabetic Retinopathy (WESDR) (Williams 2004) enrolled 919 type I and 1121 type II patients. Within five years of diagnosis, 0\% of type I patients showed evidence of DME compared with $29 \%$ after 20 years (Klein 1984). Similarly, within five years of diagnosis only $3 \%$ of type II patients had DME compared with $28 \%$ after 20 years. In this Wisconsin population the four-year incidence of clinically significant DME was $4.3 \%, 5.1 \%$, and $1.3 \%$ respectively in three patient groups (type I, insulin-treated type II, and non-insulin-treated type II) (Klein 1984). The 10-year incidence was $20.1 \%, 25.4 \%$, and $13.9 \%$ respectively in these groups (Klein 1984). Similar prevalence and incidence data have been reported in other studies that cover a wide range of countries (European, American, African, Asian, Australasian) and population groups (Williams 2004).

The presence of macular edema was associated with longer duration of diabetes, higher systolic blood pressure, insulin use, diuretic use, male gender, higher glycosylated hemoglobin, and the presence of proteinuria (Klein 1984).

In developed countries, DME is recognized as the main cause of blindness in the workingage population (20 to 74 years old) and is responsible for $12 \%$ of new cases of blindness each year (CDCP 1996). We are unaware of any data that describe the predilection of one racial group developing DME over another group.

\section{Clinical presentation and diagnosis}

The most common presenting clinical symptom of DME is blurred vision. However, a patient can have clinically significant macular edema, as defined by the Early Treatment Diabetic Retinopathy Study (ETDRS), with no symptomatic loss of central visual acuity. Other presenting symptoms can include metamorphopsia (distortion of visual image), floaters, change in contrast sensitivity, photophobia (visual intolerance to light), changes in color vision, and scotomas (localized defects of visual field).

The diagnosis is made by finding macular edema due to diabetes on the clinical examination. Generally this requires direct visualization of the macular edema that uses a high magnification stereoscopic lens system designed to view the ocular fundus. A fundus contact lens is probably the most common instrument for this purpose, but other non-contact lenses can also be used. If the thickening is sufficiently severe it can be seen with an indirect ophthalmoscope. Chronic DME can be associated with cystic degeneration of the macular retina called cystoid macular edema (CME). If CME is present it might be visible with a handheld non-stereoscopic direct ophthalmoscope. Although stereoscopic observation of the 
fundus is considered the most accepted way to diagnose DME, there is an increased use of other diagnostic tools such as stereo fundus photography, fluorescein angiography, and more recently, ocular coherence tomography.

\section{Treatment options}

In addition to glycemic control, the treatment options for DME include laser photocoagulation, intravitreal steroids, and vitrectomy. Laser photocoagulation is a therapeutic technique that uses a strong light-source to coagulate tissue. The ETDRS study recommends direct focal photocoagulation for focal macular edema and grid photocoagulation for diffuse macular edema (ETDRS 1985). Focal photocoagulation aims to close or obliterate the microaneurysms to help maintain current vision and reduce progressive visual loss. The laser light is absorbed by the blood inside the microaneurysms. Grid photocoagulation for diffuse DME aims to produce a mild to moderately intense retinal burn that may reduce leakage attributable to permeability abnormalities within dilated macular capillaries, with a positive effect on visual acuity and fluorescein leakage (Tranos 2004).

Steroids represent the traditional treatment of inflammatory eye disease because of their ability to diminish neutrophil transmigration, limit access to sites of inflammation, and decrease cytokine production. Recently the use of steroids has expanded into posterior segment disorders such as DME for its angiostatic and anti-permeability properties. For DME, intravitreal delivery techniques (intravitreal injection and steroids implant) allow for sufficiently high local concentrations of steroids to maximize their anti-inflammatory, angiostatic and anti-permeability effects in treating DME while minimizing systemic toxicity (Ciulla 2004).

Vitrectomy is considered in patients with progression in visual loss, despite treatment with laser photocoagulation and in patients with DME associated with a thickened, taut, posterior hyaloid.

\section{Rationale for a systematic review}

Several randomized controlled trials have demonstrated that traditional laser photocoagulation can reduce the risk of visual loss by $50 \%$ in patients with focal DME (DCCT 1993; DRS 1978; ETDRS 1985; UKPDS 1998). However, this treatment has had limited results for diffuse DME (Ciulla 2004; ETDRS 1985). Laser photocoagulation is a late, destructive treatment that does not specifically address the underlying cause of diabetic retinopathy. Intravitreal injection or implantation of steroids has been reported to be effective and promising in improving visual acuity in DME (Ciulla 2004; Jonas 2003; Karacorlu 2004; Kuppermann 2007; Massin 2004). Steroids administered intravitreally bypass the blood-ocular barrier to achieve therapeutic levels in the eye while minimizing systemic side effects and are thought to decrease vascular permeability during inflammation (Ciulla 2004). The short-term success must be balanced by the long-term efficacy and safety. A systematic review is therefore needed to examine the evidence regarding the effectiveness and safety of intravitreal steroids compared to other treatments in treating DME.

\section{Objectives}

The objective of this review was to assess the effectiveness and safety of intravitreal steroid therapy compared with other treatments in treating DME. 


\section{Methods}

\section{Criteria for considering studies for this review}

Types of studies-We included randomized clinical trials evaluating intravitreal steroids therapy in eyes with DME.

Types of participants-We included trials that have enrolled participants of any age and sex with any type of DME (focal, diffuse, CME) as diagnosed in the included studies. We did not exclude trials in which participants were non-responsive to previous therapy (i.e. laser photocoagulation).

Types of interventions-We included trials that have compared intravitreal steroid therapy (intravitreal injection or surgical implantation) of any dosage and duration with other treatments for DME.

\section{Types of outcome measures}

Primary outcomes: We defined in advance that the primary outcome for this review was visual acuity in the treated eye at three, six months and at different times of follow up. Visual acuity was assessed as: (1) the difference in best-corrected visual acuity as continuous data (converted into LogMAR); (2) one or more lines improvement from baseline (ETDRS, Snellen or LogMAR equivalent); (3) three or more lines improvement from baseline (ETDRS, Snellen or LogMAR equivalent).

Secondary outcomes: Secondary outcomes for this review were:

1. fluorescein leakage in the treated eye;

2. one or more grade reduction of clinical grading of macular edema (from stereoscopic color fundus photography, similar to grading employed by ETDRS, which is based on the presence of hard exudates, retinal thicknesses and distance from center of the fovea);

3. mean reduction in retinal thickness from baseline as measured by ocular coherence tomography.

We examined the secondary outcomes at different times of follow up.

Adverse effects: We tabulated all adverse effects related to intravitreal corticosteroids for treatment of DME that were reported in the included studies. Specific adverse effects of interest included but were not limited to:

1. deposition of cortisone crystals on the macular region;

2. loss of peripheral, night or color vision;

3. systemic side effects;

4. reduction in visual acuity;

5. cataract formation;

6. hemorrhage; pseudohypopyon;

7. ocular hypertension (intraocular pressure (IOP) of greater than $21 \mathrm{~mm} \mathrm{Hg}$ );

8. retinal detachment;

9. inflammation; endophthalmitis; 
10. legal blindness (visual acuity of $20 / 200$ or worse in the better eye with corrective lenses or visual field restriction to 20 degrees diameter or less (tunnel vision) in the better eye).

Quality of life measures: We planned to summarize data on quality of life by any validated measures when reported in the included studies.

Economic data: We planned to summarize data on cost and economic outcomes when reported in the included studies.

Follow up: We included trials in which participants were followed for three months or more.

\section{Search methods for identification of studies}

Electronic searches-We searched the Cochrane Central Register of Controlled Trials (CENTRAL) (which contains the Cochrane Eyes and Vision Group Trials Register) in The Cochrane Library, MEDLINE and EMBASE. We placed no language or data restrictions in the search for trials. The databases were last searched on 7 June 2007.

See: Appendices for details of search strategies for each database.

Searching other resources-We searched the reference lists of the trials included in the review for additional trials. We used the Science Citation Index to find studies that had cited the included trials. We also contacted experts in the field for information on current, past or unpublished trials. We handsearched conference proceedings of the Association for Research in Vision and Ophthalmology Annual Meeting (ARVO, Year 2002 to 2006) and the Macular Society Annual Meeting (Year 2005 and 2006) for the purpose of this review. We also handsearched Ophthalmology Times.

\section{Data collection and analysis}

Assessment of search results-Three authors independently assessed the titles and abstracts resulting from the electronic and manual searches to ascertain relevant studies for inclusion. We obtained full copies of all potentially or definitely relevant articles and all authors worked independently to determine the final eligibility. We resolved discrepancies by discussion. Whenever needed, we consulted an independent methodologist. We documented the excluded studies and reasons for exclusion (see table, 'Characteristics of excluded studies').

Assessment of methodological quality-Two authors independently assessed the included studies for sources of systematic bias according to the guidelines in Section 6 of the Cochrane Handbook for Systematic Reviews of Interventions (Higgins 2006). We considered four parameters of quality: selection bias (allocation concealment), performance bias (masking of participants); detection bias (masking of outcome assessment), and attrition bias (completeness of follow up and intention-to-treat analysis). Masking of care providers who performed a surgical procedure would not be feasible in these trials and hence not used as a measure of quality.

We graded each parameter of trial methodological quality as: A (adequate) or B (unclear or not reported) or $\mathrm{C}$ (inadequate). We resolved disagreements between the authors by discussion and/or additional methodologist adjudication. We contacted trial investigators to clarify methodological details for trials that had quality parameter grading as unclear or not reported. 
Data collection-Two authors independently extracted data onto data extraction forms developed by the Cochrane Eyes and Vision Group. We extracted the following study characteristics: study design, participants characteristics, intervention, the primary and secondary outcomes, adverse events and other relevant information. We resolved discrepancies between review authors by discussion. We contacted the study investigators for missing data. One author entered all data into Review Manager (RevMan 4.2) and this was verified using a double data-entry facility.

Data synthesis-We followed the guidelines in Section 8 of the Cochrane Handbook for Systematic Reviews of Interventions (Deeks 2006) for data analysis. For dichotomous outcomes, we calculated a summary relative risk. For continuous outcomes, we calculated the mean difference. Trials included in this review comprised a mixture of change from baseline and final value scores. We decided to combine trials with change from baseline outcomes in a meta-analysis with final measurement outcomes. In a randomized trial, the difference in mean final values would on average be the same as the difference in mean change scores (Deeks 2006).

Before combining the data, we qualitatively assessed heterogeneity by examining the characteristics of each study. We further examined statistical heterogeneity and inconsistency between studies using the forest plots, the results of the chi-square test and the value of I-squared statistics. If no substantial clinical or statistical heterogeneity was detected, we combined the results in a meta-analysis using a fixed-effect model. If there was heterogeneity that could not readily be explained, we incorporated the heterogeneity into a random-effects model. If substantial heterogeneity was observed, we presented the results in a tabulated summary.

We did not perform subgroup analyses according to characteristics such as dose of triamcinolone, types of diabetes, types of macular edema, duration of diabetes (less than five years, five to 30 years, more than 30 years), insulin use, baseline visual acuity and route of steroid administration because of insufficient data on these characteristics.

Sensitivity analysis-We did not conduct sensitivity analysis to determine the impact of exclusion of studies with lower methodological quality, unpublished data, and industryfunded studies, as only a few trials were included in this review. Instead, we qualitatively evaluated the influence of these studies.

\section{Results}

\section{Description of studies}

Results of the search-The electronic searches revealed 486 titles and abstracts. Searching the Science Citation Index yielded an additional 32 titles and abstracts. We identified six more abstracts from handsearching conference proceedings. We identified two news articles reporting results of trials from handsearching Ophthalmology Times. Out of a total of 526 reports, we thought 22 were relevant. After examining the full text, we excluded seven articles: four for which the comparison intervention did not meet the inclusion criteria; two which were not RCTs; and one for which the test intervention did not meet the inclusion criteria. The remaining 15 articles reported seven distinct trials for inclusion in this review.

We contacted experts in this field and identified one ongoing study (see table, 'Characteristics of ongoing studies'). We will update the review with data from this study as it becomes available. 


\section{Included studies}

Types of participants: We included seven studies from five countries (Australia, France, Germany, Italy, and the United States) with a total of 632 DME eyes in the review. The trials varied in size with five enrolling 30 to 80 DME eyes and the largest two enrolling 172 and 197 DME eyes. Participants were male and female adults. We found clinical heterogeneity in several areas. Jonas 2006, Kuppermann 2007, Pearson 2002 and Sutter 2004 included patients with persistent DME for at least three months after adequate laser photocoagulation treatment; Avitabile 2005 included patients without prior laser procedure. Participants varied in types of DME. Avitabile's study was on CME, generally considered to be a more severe and more chronic form of edema, and included patients with DME, branch retinal vein occlusion (BRVO), and central retinal vein occlusion (CRVO). Since the results were tabulated for each disease entity separately, the results for DME eyes could be singled out for use in our analysis. Kuppermann's study also enrolled participants with DME, BRVO, CRVO, uveitis and Irvine-Gass syndrome. We extracted DME results for analysis. The other studies did not specifically address the presence or absence of CME, but generally defined the edema as diffuse or focal, and as persistent or refractory. It is possible that some of these patients may also have had CME. The duration of diabetes, duration of DME, baseline macular edema, baseline retinal thickness and baseline IOP were not explicitly reported in most studies. Of the two studies reporting baseline retinal thickness (Avitabile 2005; Sutter 2004), the baseline values were comparable between treatment arms. Four studies reported comparable baseline visual acuity (Avitabile 2005; Jonas 2006; Kuppermann 2007; Sutter 2004). Two trials were reported in abstracts only (Pearson 2002; Pearson 2005) and no detailed information could be extracted. Audren 2006 consisted of randomized and non-randomized participants. We were unable to extract data for randomized participants based on the report.

Types of intervention: Two types of interventions were evaluated in the included trials: intravitreal steroid injection and intravitreal steroid implantation. Of the four intravitreal injection trials, three (Audren 2006; Jonas 2006; Sutter 2004) compared intravitreal triamcinolone acetonide injection (IVTA) with sham procedure or no treatment; one (Avitabile 2005) compared IVTA with macular laser grid photocoagulation (MLG). Audren 2006, Avitabile 2005 and Sutter 2004 used 4 mg IVTA. Repeat injection was allowed in Avitabile 2005 and Sutter 2004, and was not reported in Audren 2006. Jonas 2006 used a different dosage of $20 \mathrm{mg}$. The preoperative preparation and surgical techniques of IVTA were comparable between studies. Two trials (Pearson 2002; Pearson 2005) compared intravitreal fluocinolone acetonide implantation of different dosage with standard of care (MLG or observation). The remaining one trial (Kuppermann 2007) compared dexamethasone DDS, 350 or 700 ug to observation. Avitabile 2005 and Pearson 2002 also included a third treatment arm but this was not evaluated in the review.

Types of outcomes: All trials considered visual acuity as the major outcome. Exact definition and measurement of visual acuity varied across trials. One study (Avitabile 2005) reported final values; three studies (Audren 2006; Jonas 2006; Sutter 2004) reported the degree of change relative to pre-injection level; five studies (Jonas 2006; Kuppermann 2007; Pearson 2002; Pearson 2005; Sutter 2004) reported three or more lines improvement; two studies (Jonas 2006; Sutter 2004) reported one or more lines improvement. Visual acuity measurements were by ETDRS chart, the most standardized method, in four trials (Audren 2006; Avitabile 2005; Kuppermann 2007; Sutter 2004).

Retinal thickness data were reported in four trials (Audren 2006; Avitabile 2005; Kuppermann 2007; Sutter 2004) and were discussed in all trials. Improvement of macular 
edema data were quantitatively included in two trials (Pearson 2005; Sutter 2004) and was discussed in Pearson 2002. One trial (Kuppermann 2007) reported on fluorescein leakage.

Adverse events of interest included IOP increase (reported in seven trials), trabeculectomy or other glaucoma procedures (reported in three trials), cataract progression or cataract surgery (reported in three trials), and reduction in visual acuity (reported in three trials). Other less common adverse effects, including injection complication, ptosis, macular edema progression, infectious endophthalmitis, conjunctival ulcer and corneal decompensation, were also reported. None of the trials reported on cortisone crystal deposition, loss of color vision, systemic side effects or incidence of legal blindness. Important complications are tabulated in Table 1 'Complications reported in included studies'.

None of the trials reported quality of life measures or economic data.

Excluded studies-See: Characteristics of excluded studies for further details.

\section{Risk of bias in included studies}

Overall, two (Avitabile 2005; Sutter 2004) of the seven trials included in this review were at low risk of bias. Methodological quality parameters, including allocation concealment, masking of outcome assessment, comparability of follow up and intention-to-treat analysis, were adequately addressed. One trial (Kuppermann 2007) was graded at median risk of bias because method of allocation concealment was not reported and a larger proportion of participants lost to follow up in the observational arm. We were unable to assess the methodological quality of two trials (Pearson 2002; Pearson 2005). The correspondence from the authors did not add further information. The remaining two studies (Audren 2006; Jonas 2006) were graded at high risk of bias because the method of allocation concealment and masking of the outcome assessor were not reported, and an intention-to-treat analysis was not performed. The results of our quality assessment are described in detail in the 'Characteristics of included studies' table.

\section{Effects of interventions}

Intravitreal triamcinolone acetonide injection versus other treatment-Four trials (Audren 2006; Avitabile 2005; Jonas 2006; Sutter 2004) assessed IVTA injection versus other treatments (no treatment, sham procedure or MLG). We were unable to use inadequately analyzed data from Audren 2006. Meta-analyses were limited to trials with data reported on prespecified outcomes at various follow-up times. We pooled the results whenever justified. Otherwise, a single estimate from one study was presented.

Change in visual acuity (LogMAR) (Analysis 1.1): Two studies reported mean change in visual acuity from baseline (Jonas 2006; Sutter 2004). One study (Avitabile 2005) reported the final value. Since participants in both groups in a randomized trial are comparable at baseline due to randomization, comparison of the final mean visual acuity estimates the same treatment effects as comparison of mean change from baseline values. Sixty per cent of participants (26/43) in Sutter 2004 had both eyes randomized. The authors applied statistical methods (generalized estimating equations (GEE)) to allow for correlations between paired eyes. We procured from the investigators the effect estimates and their standard errors and meta-analyzed them with other studies using the generic inverse variance method in RevMan. Seven per cent (2/38) of participants had both eyes randomized in Jonas 2006. The authors failed to account for the correlation statistically; however the influence would be minimal. The unit of randomization was unclear in Avitabile 2005. Studies reported various units for visual acuity measurement (letters, lines and LogMAR). We converted them into LogMAR for analysis. 
At three months, the mean difference in visual acuity (change in mean visual acuity in the IVTA arm minus change in mean visual acuity in the comparison arm) in a fixed-effect model meta-analysis with three trials was $-0.15 \operatorname{LogMAR}(95 \% \mathrm{CI}-0.21$ to -0.09$)$ in favor of IVTA. The chi-square test $(6.93, \mathrm{df}=2 ; \mathrm{P}=0.03)$ and I-square value $(71.1 \%)$ suggested statistical heterogeneity. Using the random-effects model, the mean difference in visual acuity was $-0.20 \operatorname{LogMAR}(95 \% \mathrm{CI}-0.34$ to -0.06$)$ in favor of IVTA. Because the randomeffects model suggested a stronger effect and because the number of trials was small, we preferred results based on the fixed-effect model.

At six months, the mean difference in visual acuity in a meta-analysis with two trials (Avitabile 2005; Jonas 2006) was $-0.23 \operatorname{LogMAR}(95 \% \mathrm{CI}-0.33$ to -0.13 ) in favor of IVTA. The chi-square test for heterogeneity was $0.49, \mathrm{df}=1(\mathrm{P}=0.48)$ and the I-square value was $0 \%$.

At nine months, the mean difference in visual acuity was $-0.29 \operatorname{LogMAR}(95 \% \mathrm{CI}-0.47$ to -0.11 ) in favor of IVTA (Avitabile 2005).

At 24 months, the mean difference in visual acuity was $-0.11 \operatorname{LogMAR}(95 \% \mathrm{CI}-0.20$ to -0.03 ) in favor of IVTA (Sutter 2004).

Gain of one or more lines visual acuity (Analysis 1.2): At three months, the RR for one or more lines improvement in visual acuity was 2.85 (95\% CI 1.59 to 5.10) in favor of IVTA in a meta-analysis of two trials (Jonas 2006; Sutter 2004). Although Jonas 2006 employed a higher dosage ( $20 \mathrm{mg}$ in Jonas versus $4 \mathrm{mg}$ in Sutter), no greater benefit was observed. The chi-square test $(0.91, \mathrm{df}=1 ; \mathrm{P}=0.34)$ and the $\mathrm{I}$-square value $(0 \%)$ did not demonstrate statistical heterogeneity.

At six months, there was no statistically significant difference in improvement by one or more lines vision between IVTA and sham procedure groups. The RR was 1.25 (95\% CI 0.66 to 2.38) (Jonas 2006).

At 24 months, the RR for one or more lines improvement in vision was 2.17 (95\% CI 1.15 to 4.11) in favor of IVTA (Sutter 2004).

Gain of three or more lines visual acuity (Analysis 1.3): At three months, we did not find evidence of effect on three or more lines improvement in visual acuity comparing IVTA to sham procedure in a meta-analysis with two studies (Jonas 2006; Sutter 2004). The RR was 1.92 (95\% CI 0.50 to 7.40 ). The chi-square test did not reveal statistically significant heterogeneity $(1.70, \mathrm{df}=1 ; \mathrm{P}=0.19)$ and the I-square value was $41.3 \%$. The distinct direction of study effect estimates, with one favoring each arm, and the small number of events limited the ability of meaningful statistical analysis and explained partially the uncertainty associated with the pooled estimate.

At 24 months, we found no evidence of effect on three or more lines improvement in visual acuity comparing IVTA to sham procedure. The RR was 4.12, with a wide CI (95\% CI 0.48 to 34.99) (Sutter 2004). Lack of adequate outcomes affected the precision and interpretation of this estimate.

Change in retinal thickness (Analysis 1.4): One study reported mean change in retinal thickness from baseline with correction for paired eyes correlation (Sutter 2004). One study reported the final value (Avitabile 2005). We pooled the change score and the final value using the generic inverse variance method as described above. 
At three months, the mean difference in retinal thickness (change in retinal thickness in the IVTA arm minus the change in mean retinal thickness in the comparison arm) in a metaanalysis with two studies was -131.97 um (95\% CI -169.08 to -94.86) in favor of IVTA. The chi-square test for heterogeneity did not show statistical significance $(1.95, \mathrm{df}=1 ; \mathrm{P}=$ 0.16 ) and the I-square value was $48.6 \%$.

At six months, the mean difference in retinal thickness comparing IVTA with MLG was -135.00 um (95\% CI -194.50 to -75.50) in favor of IVTA (Avitabile 2005).

At nine months, the mean difference in retinal thickness comparing IVTA with MLG was -133.00 um (95\% CI -199.86 to -66.14) in favor of IVTA (Avitabile 2005).

At 24 months, the mean difference in retinal thickness comparing IVTA with MLG was -59.00 um (95\% CI -103.50 to -14.50$)$ in favor of IVTA (Sutter 2004).

Resolution of at least one grade of macular edema (Analysis 1.5): At three months, the RR for at least one grade macular edema resolution comparing IVTA with sham procedure was 5.15 (95\% CI 2.23 to 11.88) in favor of IVTA injection (Sutter 2004).

\section{Intravitreal steroid implants (FAI or dexamethasone DDS) versus other}

treatment-Two trials (Pearson 2002; Pearson 2005) evaluated FAI versus other treatment (standard of care or observation). One trial (Kuppermann 2007) examined dexamethasone DDS, 350 or $700 \mathrm{ug}$ versus observation. We were not able to perform any meta-analysis because data were insufficient. Instead, we presented the effect estimate and it's associated confidence interval for each trial separately.

\section{FAl versus other treatment}

Gain of three or more lines visual acuity (Analysis 2.1): At 12 months, we did not find evidence of effect on three or more lines improvement in visual acuity comparing FAI with standard of care or observation. The RR was 2.73 (95\% CI 0.63 to 11.92), which covered the null value (Pearson 2002).

At 36 months, we found a marginal statistically significant effect on three or more lines improvement in visual acuity comparing FAI with standard of care or observation. The RR was 1.93 (95\% CI 1.02 to 3.66) (Pearson 2005).

DDS implant versus other treatment: The dexamethasone DDS trial enrolled participants with various underlying causes of macular edema. In the subgroup affected by DME, 33/57 $(58 \%)$ in the DDS $700 \mathrm{ug}$ group showed a two-line improvement in vision compared to $12 / 57(21 \%)$ in the observation group $(\mathrm{RR}=2.75 ; 95 \% \mathrm{CI} 1.59$ to 4.76$)$ at three months.

Complications: We were unable to extract adequate data from the published reports or procure additional information from the investigator to compare complication rates in different trials according to time of occurrence. Consequently no meta-analysis was performed. We summarized important complications reported in the included trials in Table 1 'Complications reported in included studies'. This counting procedure did not establish differences in defining the complications of each study.

In summary, increased IOP associated with intervention was observed in all trials, ranging from $12 \%$ to $65 \%$ of treated eyes. From the reports, $30 \%$ of eyes receiving test intervention required glaucoma treatment (surgical procedure or medication), $0 \%$ to $43 \%$ of eyes experienced cataract progression or cataract surgery. Severe reduction in visual acuity (three or more lines) was not uncommon in eyes receiving FAI (14\% to 19\%). Other adverse 
events reported in these studies included one IVTA patient with infectious endophthalmitis which maintained improved vision during the study; two IVTA patients with ptosis; another with a conjunctival ulcer, and one dexamethasone DDS 350 ug patient with extramacular tractional retinal detachment. There were no reports of lens damage or retinal holes in these studies.

\section{Discussion}

Macular edema is an important cause of poor vision in diabetes, and consequently substantial research has been performed to devise ways to stabilize, improve, or prevent DME. One recent intervention for the presence of DME has been the use of intravitreal steroids in the form of triamcinolone acetate injections, or as an implant of fluocinolone acetonide or dexamethasone DDS. Intravitreal steroids have been used in a varying dose range, given once or in repeat doses, as a standalone therapy, in conjunction with laser therapy, or as follow-up therapy when standard laser therapy has failed. There have been many short-term trials on the treatment of DME using intraocular steroids, many uncontrolled, with varying results from which varying conclusions can be inferred (Avitabile 2005; Jonas 2004; Jonas 2006; Massin 2004). Consequently, this review is an attempt to analyze the available randomized clinical trials to determine the effectiveness and safety of intraocular steroids in treating DME.

\section{Summary of main results}

In this systematic review of randomized clinical trials, evidence suggests a beneficial effect from IVTA and dexamethasone DDS. There might be evidence of benefit with the use of FAI. However, this conclusion is limited by the ways that the trial results have been reported.

With respect to IVTA, evidence suggests a treatment effect in favor of IVTA at three, six, nine and 24 months follow up measured by improvement in LogMAR visual acuity (Analysis 1.1). Meta-analysis of two studies (Analysis 1.2) at three months showed a one line visual improvement favoring IVTA. However, at six months there was no statistically significant difference (Jonas 2006), but again at 24 months the results were statistically significant for an IVTA treatment effect (Sutter 2004). Since Jonas only gave a single injection of $20 \mathrm{mg}$ IVTA, the drug may have gradually disappeared from the eye leading to a drop off in effect, while Sutter's patients could receive a reinjection of IVTA if there was a five letter or greater decline in vision. Thus the retreatment can be viewed as promoting a more sustained effect. Since no quality of life or economic data are available in any of these studies, it is difficult to assign meaning to a one line change in vision. However, it is a trend in favor of IVTA use. Two sets of data for a three line improvement in vision were available (Analysis 1.3). We did not find evidence of a three line or more improvement comparing IVTA to a sham injection at three months. Similarly at 24 months data from one trial also failed to show a statistically significant effect. The small number of events makes meaningful analysis limited.

Reduction in retinal thickness is considered a mechanism for visual improvement in the treatment of macular edema. Therefore a corresponding reduction in thickness would be expected if there was a trend toward visual improvement. At three months, the meta-analysis of two studies (Avitabile 2005; Sutter 2004) (Analysis 1.4) showed a reduction in retinal thickness of the IVTA arm compared to controls. The relative reduction appeared to be sustained at six, nine and 24 months. Also Sutter 2004 demonstrated a resolution of one grade of macular edema in favor of IVTA (Analysis 1.5). 
Since current therapy is directed primarily at stabilizing or reducing the loss of vision, it is important to know if intraocular steroids might, as a side effect, promote the loss of vision. In Jonas 2006 at six months only 2 of 23 IVTA eyes experienced decreased visual acuity compared to 2 of 9 (22\%) controls ( $R R=0.39 ; 95 \%$ CI 0.06 to 2.37). In Sutter 2004 at two years 6 of 34 IVTA eyes had decreased visual acuity compared to 13 of 35 control eyes (RR $=0.48 ; 95 \% 0.20$ to 1.11 ). These results suggest that IVTA does not materially contribute to an increased risk of visual loss.

With regard to intravitreal steroid implants, two trials (Pearson 2002; Pearson 2005) evaluated the efficacy of FAI implants versus the standard of care (observation or MGL), and one trial (Kuppermann 2007) evaluated dexamethasone DDS, 350 or 700 ug versus observation. Of two FAI trials, data were reported only in abstract form, and specific details regarding patient characteristics, trial design, and complete results were not available. At 12 months the implant eyes in the first study (Pearson 2002) showed a reduction in macular edema, but no measurable improvement in visual acuity compared to the controls since the RR covered the null value (Analysis 2.1). However, at the 24-month follow up the mean change in visual acuity was a gain of $0.19 \pm 0.29 \operatorname{LogMAR}$ while the controls lost $0.04 \pm 0.30$ LogMAR (Pearson 2002). The delayed visual improvement in the FAI group may be principally attributed to masking by the cataract with vision showing improvement compared to baseline once the cataract was removed. In the second study (Pearson 2005), a marginal statistically significant effect on a three line improvement in visual acuity was reported at 36 months (Analysis 02.01), while a three line loss was found in 19\% (24/127) of the implant eyes and $16 \%(11 / 70)$ of the control eyes ( $R R=1.2 ; 95 \%$ CI 0.63 to 2.31 ). Also $58 \%$ (74/127) of implant eyes showed no evidence of edema compared to 30\% (21/70) of control eyes at 12 months $(\mathrm{RR}=1.94 ; 95 \% \mathrm{CI} 1.32$ to 2.86$)$. The dexamethasone DDS trial enrolled participants with various underlying causes of macular edema. For all participants, dexamethasone DDS was associated with improved visual acuity, reduced central retinal thickness, and improved fluorescein leakage at three months. In the subgroup affected by DME, 58\% (33/57) in the DDS 700 ug group showed a two-line improvement in vision compared to $21 \%(12 / 57)$ in the observation group ( $\mathrm{RR}=2.75$; $95 \%$ CI 1.59 to 4.76$)$.

Elevation of IOP and cataract progression occur in both IVTA and implants treated eyes but appear manageable.

\section{Strengths of the review}

To our knowledge, this is the first systematic review and meta-analysis on the topic of intravitreal steroids for macular edema in diabetes. It attempts to offer an up-to-date and complete overview of randomized trials concerning this subject.

\section{Quality of the evidence and limitations}

Limitations to our systematic review mainly stem from the inherent clinical heterogeneity in the included trials. The differences in the types of DME, background disease profile, previous DME treatment and different comparison interventions made it difficult to pool the data in an accurate manner. Furthermore, since the exact definition and measurement of outcomes, such as visual acuity and retinal thickness vary among studies, our pooled results may be biased due to misclassification. In addition, we obtained limited data and methodological details for the two FAI trials. Such methodologic limitations made it difficult to quantify the magnitude of effect of FAI and establish firm conclusions. 


\section{Authors' conclusions}

\section{Implications for practice}

Our analysis suggests that intravitreal steroid injections and implants may have some treatment effect for some cases of persistent or refractory DME in situations where the current standard of care was insufficient, but because of the varied treatment protocols, our analysis failed to identify any specific practice algorithms. Because of the relatively short half-life of IVTA, repeat injections may be required to maintain or obtain the desired effect which might increase the risk of injection-related complications such as infectious endophthalmitis, retinal tears, retinal detachment, retinal holes and vitreous hemorrhage. Intravitreal steroid implants help circumvent the complications of repeat injections and may have a more sustained effect, but they may also have a greater risk of elevated IOP requiring medical and surgical intervention and a greater risk of cataract progression requiring surgery. Finally, these studies do not readily address the treatment effect of intravitreal steroids on other stages of DME, especially the earlier stage either as standalone therapy or in combination with other therapies, such as laser photocoagulation.

\section{Implications for research}

The seven studies (three IVTA studies and four intravitreal steroid implantation studies) in our report dealt primarily with persistent or refractory DME and raise important issues including the role of injections versus implantation, dosage, timing of the intervention, type of edema to be treated (chronic versus acute, diffuse versus focal versus cystoid) and the role of steroids in relationship to other forms of treatment such as laser therapy. The question arises whether the treatment should be reserved for chronic refractory edema or if it may be useful in the earlier stages of DME. Economic and quality of life data also need to be considered as well as the rate and severity of complications, how best to manage them, and the overall effect of these complications on the ultimate value of the treatment. One ongoing trial has been organized to address some of these issues (Ip 2004). The trial is investigating whether IVTA at a dose of $1 \mathrm{mg}$ versus a dose of $4 \mathrm{mg}$ produce greater benefit, with an acceptable safety profile, compared to macular laser photocoagulation in the treatment of DME (planned to enroll 795 patients; primary outcome at three years). We will update the review with data from this study as it becomes available.

\section{Supplementary Material}

Refer to Web version on PubMed Central for supplementary material.

\section{Acknowledgments}

We thank the CEVG editorial team for devising and running the electronic search strategies. We also thank Barbara Hawkins and Anuradha Satyamurthy for their comments on this review and Andrew Chang, Swaroop Vedula and Zbys Fedorowicz for their comments on the protocol of this review.

Declarations of interest

Bausch \& Lomb provides intraocular steroid delivery systems, some of which are still undergoing clinical trials. The University of Rochester Eye Institute receives grants and other support from Bausch \& Lomb.

Sources of support

Internal sources

- $\quad$ No sources of support provided

External sources

- Contract N-01-EY2-1003, National Eye Institute, National Institutes of Health, USA 


\section{References to studies}

\section{Included studies}

Audren 2006 Published and unpublished data Audren F, Erginay A, Haouchine B, Benosman R, Conrath J, Bergmann JF, et al. Intravitreal triamcinolone acetonide for diffuse diabetic macular oedema: 6-month results of a prospective controlled trial. Acta ophthalmologica Scandinavica. 2006; 84(5):624-630. [PubMed: 16965492] Massin P, Audren F, Haouchine B, Erginay A, Bergmann JF, Benosman R, et al. Intravitreal triamcinolone acetonide for diabetic diffuse macular edema: preliminary results of a prospective controlled trial. Ophthalmology. 2004; 111(2):218-224. [PubMed: 15019365]

Avitabile 2005 Avitabile T, Longo A, Reibaldi A. Intravitreal triamcinolone compared with macular laser grid photocoagulation for the treatment of cystoid macular edema. American Journal of Ophthalmology. 2005; 140(4):695-702. [PubMed: 16226521]

Jonas 2006 Jonas JB, Kampperter BA, Harder B, Vossmerbaeumer U, Sauder G, Spandau UH. Intravitreal triamcinolone acetonide for diabetic macular edema: a prospective, randomized study. Journal of Ocular Pharmacology \& Therapeutics. 2006; 22(3):200-207. [PubMed: 16808682]

Kuppermann 2007 Unpublished data only Kuppermann BD, Blumenkranz MS, Haller JA, Williams GA. Posurdex Study Group. An Intravitreous Dexamethasone Bioerodible Drug Delivery System for the Treatment of Persistent Diabetic Macular Edema. Association for Research in Vision and Ophthalmology Annual Meeting. 2003 Kuppermann BD, Blumenkranz MS, Haller JA, Williams GA, Weinberg DV, Chou C, et al. Randomized Controlled Study of an Intravitreous Dexamethasone Drug Delivery System in Patients With Persistent Macular Edema. Archives of Ophthalmology. 2007; 125(3):309-317. [PubMed: 17353400]

Pearson 2002 Unpublished data only Nancy Groves, Reviewed by Pearson PA. Steroids implant reduces retinal thickness, improves vision. Ophthalmology Times. 2004 Nov 15.:24-26. Pearson PA, Baker CW, Eliott D, Ip MS, Morese LS, Callanan DG. Fluocinolone Acetonide Intravitreal Implant for Diabetic Macular Edema: 2 Year Results. Association for Research in Vision and Ophthalmology Annual Meeting. 2004 Pearson PA, Baker CW, Eliott D, Ip MS, Morese LS, Callanan DG. Fluocinolone Acetonide Intravitreal Implant in Patients with Diabetic Macular Edema. American Academy of Ophthalmology Annual Meeting. 2002 Pearson PA, Eliott D, Baker CW, Ip MS, Morese LS, Callanan DG. Fluocinolone Acetonide Intravitreal Implant in Patients with Diabetic Macular Edema. Association for Research in Vision and Ophthalmology Annual Meeting. 2003

Pearson 2005 Unpublished data only Nancy Groves, Reviewed by Pearson PA. Patients with DME have response to fluocinolone acetonide intravitreal implant in study outcomes. Ophthalmology Times. 2006 Aug 1.:38. Pearson PA, Bevy B. Fluconolone Acetonide Implant Study Group. Fluocinolone Acetonide Intravitreal Implant to Treat Diabetic Macular Edema: 2-year Results of a Multi-Center Clinical Trial. Association for Research in Vision and Ophthalmology Annual Meeting. 2005 Pearson PA, Levy B, Comstock T. Fluocinolone Acetonide Implant Study Group. Fluocinolone Acetonide Intravitreal Implant to Treat Diabetic Macular Edema: 3-Year Results of a Multi-Center Clinical Trial. Association for Research in Vision and Ophthalmology Annual Meeting. 2006

Sutter 2004 Published and unpublished data Gillies MC, Sutter FK, Simpson JM, Larsson J, Ali H, Zhu M. Intravitreal Triamcinolone for Refractory Diabetic Macular Edema Two-Year Results of a Double-Masked, Placebo-Controlled, Randomized Clinical Trial. Ophthalmology. 2006; 113(9): 1533-1538. [PubMed: 16828501] Sutter FK, Simpson JM, Gillies MC. Intravitreal triamcinolone for diabetic macular edema that persists after laser treatment: three-month efficacy and safety results of a prospective, randomized, double-masked, placebo-controlled clinical trial. Ophthalmology. 2004; 111(11):2044-2049. [PubMed: 15522370]

\section{Excluded studies}

Bandello 2004 Unpublished data only Bandello F, Polito A, Dimastrogiovanni A, Palsslos I. Intravitreal triamcinolone associated with grid laser photocoagulation for diffuse diabetic macular edema. Macular Society Annual Meeting. 2004 
Bonini-Filho 2005 Bonini-Filho MA, Jorge R, Barbosa JC, Calucci D, Cardillo JA, Costa RA. Intravitreal injection versus sub-Tenon's infusion of triamcinolone acetonide for refractory diabetic macular edema: a randomized clinical tiral. Investigative Ophthalmology \& Visual Science. 2005; 46(10):3845-3849. [PubMed: 16186372]

Cardillo 2005 Cardillo JA, Melo LA Jr, Costa RA, et al. Comparison of intravitreal versus posterior sub-Tenon's capsule injection of triamcinolone acetonide for diffuse diabetic macular edema. Ophthalmology. 2005; 112(9):1157-1163.

Er $2005 \mathrm{Er} \mathrm{H}$, Yilmaz H. Intravitreal cortisone injection for refractory diffuse diabetic macular edema. Ophthalmologica. 2005; 219(6):394-400. [PubMed: 16286802]

Jonas 2004 Jonas JB, Harder B, Kamppeter BA. Inter-eye difference in diabetic macular edema after unilateral intravitreal injection of triamcinolone acetonide. American Journal of Ophthalmology. 2004; 138(6):970-977. [PubMed: 15629288]

Spandau 2005 Spandau UH, Derse M, Schmitz-Valckenberg P, Papoulis C, Jonas JB. Dosage dependency of intravitreal triamcinolone acetonide as treatment for diabetic macular oedema. British Journal of Ophthalmology. 2005; 89(8):999-1003. [PubMed: 16024853]

Verma 2004 Verma LK, Vivek MB, Kumar A, Tewari HK, Venkatesh P. A prospective controlled trial to evaluate the adjunctive role of posterior subtenon triamcinolone in the treatment of diffuse diabetic macular edema. Journal of Ocular Pharmacology \& Therapeutics. 2004; 20(4):277-284. [PubMed: 15321022]

\section{Studies awaiting classification}

\section{Ongoing studies}

Ip 2004 Unpublished data only

\section{Other references}

\section{Additional references}

Aroca 2004 Aroca PR, Salvat M, Fernandez J, Mendez I. Risk factors for diffuse and focal macular edema. Journal of Diabetes Complications. 2004; 18(4):211-215.

CDCP 1996 Centers for Disease Control and Prevention. Blindness caused by diabetes: Massachusetts, 1987-1994. Morbidity and Mortality Weekly Report. 1996; 45(43):937-941. [PubMed: 8927019]

Ciulla 2004 Ciulla TA, Walker JD, Fong DS, Criswell MH. Corticosteroids in posterior segment disease: an update on new delivery systems and new indications. Current Opinions in Ophthalmology. 2004; 15(3):211-220.

Cunha-Vaz 1998 Cunha-Vaz J. Diabetic macular edema. European Journal of Ophthalmology. 1998; 8:127-130. [PubMed: 9793763]

DCCT 1993 The Diabetes Control and Complications Trial (DCCT) Research Group. The effect of intensive treatment of diabetes on the development and progression of long-term complications in insulin-dependent diabetes mellitus. New England Journal of Medicine. 1993; 329:977-986. [PubMed: 8366922]

Deeks 2006 Deeks JJ, Higgins JPT, Altman DG. Analysing and presenting data. Cochrane Handbook for Systematic Reviews of Interventions 4.2.6 [updated September 2006]; Section 8. The Cochrane Library. 2006; (Issue 4)Chichester, UKJohn Wiley \& Sons, Ltd

DRS 1978 Diabetic Retinopathy Study Research Group. Photocoagulation treatment of proliferative diabetic retinopathy: the second report of DRS findings. Ophthalmology. 1978; 85:82-106. [PubMed: 345173]

ETDRS 1985 Early Treatment Diabetic Retinopathy Study Research Group. Photocoagulation for diabetic macular edema. Early Treatment Diabetic Retinopathy Study report number 1. Archives of Ophthalmology. 1985; 103(12):1796-1806. [PubMed: 2866759]

Glanville 2006 Glanville JM, Lefebvre C, Miles JN, Camosso-Stefinovic J. How to identify randomized controlled trials in MEDLINE: ten years on. Journal of the Medical Library Association. 2006; 94(2):130-136. [PubMed: 16636704] 
Higgins 2006 Higgins JPT, Green S. Assessment of study quality. Cochrane Handbook for Systematic Reviews of Interventions 4.2.6 [updated September 2006]; Section 6. The Cochrane Library. 2006; (Issue 4)Chichester, UKJohn Wiley \& Sons, Ltd

Jonas 2003 Jonas JB, Kreissig I, Sofker A, Degenring RF. Intravitreal injection of triamcinolone for diffuse DME. Archives of Ophthalmology. 2003; 121:57-61. [PubMed: 12523885]

Karacorlu 2004 Karacorlu M, Ozdemir H, Karacorlu S, Alacali N, Mudun B, Burumcek E. Intravitreal triamcinolone as a primary therapy in diabetic macular oedema. Eye. 2005; 19(4):382-386. [PubMed: 15309024]

Klein 1984 Klein R, Klein BE, Moss SE, Davis MD, DeMets DL. The Wisconsin epidemiologic study of diabetic retinopathy. IV. Diabetic macular edema. Ophthalmology. 1984; 91(12):1464-1474. [PubMed: 6521986]

Massin 2004 Massin P, Audren F, Haouchine B, Erginay A, Bergmann JF, Benosman R, et al. Intravitreal triamcinolone acetonide for diabetic diffuse macular edema: preliminary results of a prospective controlled trial. Ophthalmology. 2004; 111(2):218-224. [PubMed: 15019365]

Tranos 2004 Tranos PG, Wickremasinghe SS, Stangos NT, Topouzis F, Tsinopoulos I, Pavesio CE. Macular edema. Survey of Ophthalmology. 2004; 49(5):470-490. [PubMed: 15325193]

UKPDS 1998 UKPDS Group. Intensive blood-glucose control with sulphonylureas or insulin compared with conventional treatment and risk of complications in patients with type 2 diabetes (UKPDS 33). Lancet. 1998; 352(1998):837-853. [PubMed: 9742976]

Williams 2004 Williams R, Airey M, Baxter H, Forrester J, Kennedy-Martin T, Girach A. Epidemiology of diabetic retinopathy and macular oedema: a systematic review. Eye. 2004; 18(10):963-983. [PubMed: 15232600]

\title{
Appendices
}

\section{CENTRAL search strategy for Issue 2, 2007}

\author{
\#1 MeSH descriptor Diabetic Retinopathy \\ \#2 macular edema cystoid \\ \#3 macular degeneration \\ \#4 macula* near edema \\ \#5 macula* near oedema \\ \#6 DME \\ \#7 DMO \\ \#8 $\mathrm{CME}$ \\ \#9 CSME \\ \#10 macula* near swell* \\ \#11 microaneurysm* \\ \#12 dilat* near capillar*
}

\#13 (\#1 OR \#2 OR \#3 OR \#4 OR \#5 OR \#6 OR \#7 OR \#8 OR \#9 OR \#10 OR \#11 OR \#12)

\#14 MeSH descriptor Steroids

\#15 MeSH descriptor Triamcinolone

\#16 triamcin*

\#17 steroid* or glucocorticoid* 


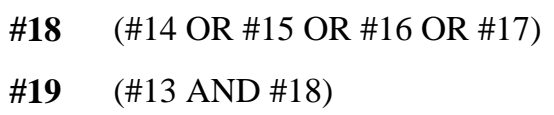

\section{MEDLINE search strategy used up to June 2007}

1. exp clinical trial/ [publication type]

2. (randomized or randomised).ab,ti.

3. placebo.ab,ti.

4. dt.fs.

5. randomly.ab,ti.

6. trial.ab,ti.

7. groups.ab,ti.

8. or $/ 1-7$

9. exp animals/

10. exp humans/

11. 9 not (9 and 10)

12. 8 not 11

13. exp diabetic retinopathy/

14. exp macular edema cystoid/

15. exp macular degeneration/

16. (macula $\$$ adj2 edema).tw.

17. (macula $\$$ adj 2 oedema).tw.

18. DME.tw.

19. DMO.tw.

20. CME.tw.

21. CSME.tw.

22. (macula $\$$ adj2 swell\$).tw.

23. microaneurysm $\$$.tw.

24. (dilat\$ adj2 capillar\$).tw.

25. or/13-24

26. exp steroids/

27. exp triamcinolone/

28. triamcin $\$$.tw.

29. (steroid\$ or glucocorticoid\$).tw.

30. or $/ 26-29$

31. 25 and 30

32. 12 and 31 
The search filter for trials at the beginning of the MEDLINE strategy is from the published paper by Glanville (Glanville 2006).

\section{EMBASE search strategy used up to June 2007}

1. exp randomized controlled trial/

2. exp randomization/

3. exp double blind procedure/

4. exp single blind procedure/

5. random\$.tw.

6. or $/ 1-5$

7. (animal or animal experiment).sh.

8. human.sh.

9. 7 and 8

10. 7 not 9

11. 6 not 10

12. exp clinical trial/

13. (clin\$ adj3 trial\$).tw.

14. ((singl\$ or doubl\$ or trebl\$ or tripl\$) adj3 (blind $\$$ or mask $\$)$ ).tw.

15. exp placebo/

16. placebo\$.tw.

17. random $\$ . t w$.

18. exp experimental design/

19. exp crossover procedure/

20. exp control group/

21. exp latin square design/

22. or $/ 12-21$

23. 22 not 10

24. 23 not 11

25. exp comparative study/

26. exp evaluation/

27. exp prospective study/

28. (control\$ or prospectiv\$ or volunteer\$).tw.

29. or $/ 25-28$

30. 29 not 10

31. 30 not (11 or 23$)$

32. 11 or 24 or 31 
33. exp diabetic retinopathy/

34. exp retina macula cystoid edema/

35. exp retina macula degeneration/

36. (macula $\$$ adj 2 edema).tw.

37. (macula $\$$ adj 2 oedema).tw.

38. DME.tw.

39. DMO.tw.

40. CME.tw.

41. CSME.tw.

42. (macula $\$$ adj 2 swell\$).tw.

43. microaneurysm $\$$.tw.

44. (dilat\$ adj2 capillar\$).tw.

45. or/33-44

46. exp steroid/

47. exp triamcinolone/

48. triamcin $\$ . t w$.

49. (steroid\$ or glucocorticoid\$).tw.

50. or $/ 46-49$

51. 45 and 50

52. 32 and 51 


\begin{tabular}{|c|c|c|c|c|c|c|c|}
\hline 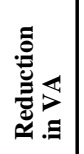 & 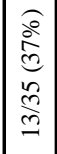 & $\frac{a}{z}$ & 点 & 点 & 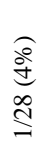 & $\stackrel{\Re}{\Xi}$ & $\begin{array}{l}\widehat{o} \\
\frac{\partial}{d} \\
o \\
\frac{\partial}{\gamma}\end{array}$ \\
\hline 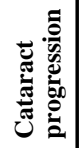 & 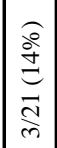 & $\mid \begin{array}{c}\widehat{0} \\
\stackrel{0}{0} \\
0\end{array}$ & $\frac{\tilde{z}}{\mathrm{z}}$ & 良 & 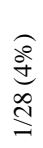 & $\frac{\tilde{z}}{\mathrm{z}}$ & $\tilde{z}$ \\
\hline
\end{tabular}

\begin{tabular}{|c|c|c|c|c|c|c|c|c|}
\hline & & & & & & & & \\
\hline 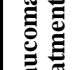 & & & & & & & & \\
\hline 嘕 & & 学 & $\mathrm{z}$ & $z$ & & $\tilde{z}$ & $\frac{n}{z}$ & 点 \\
\hline
\end{tabular}

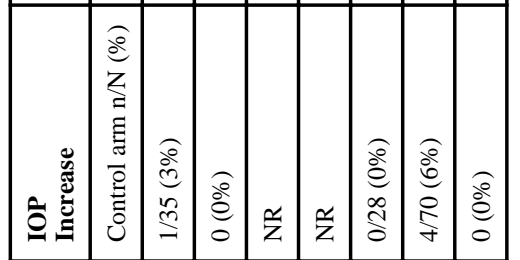

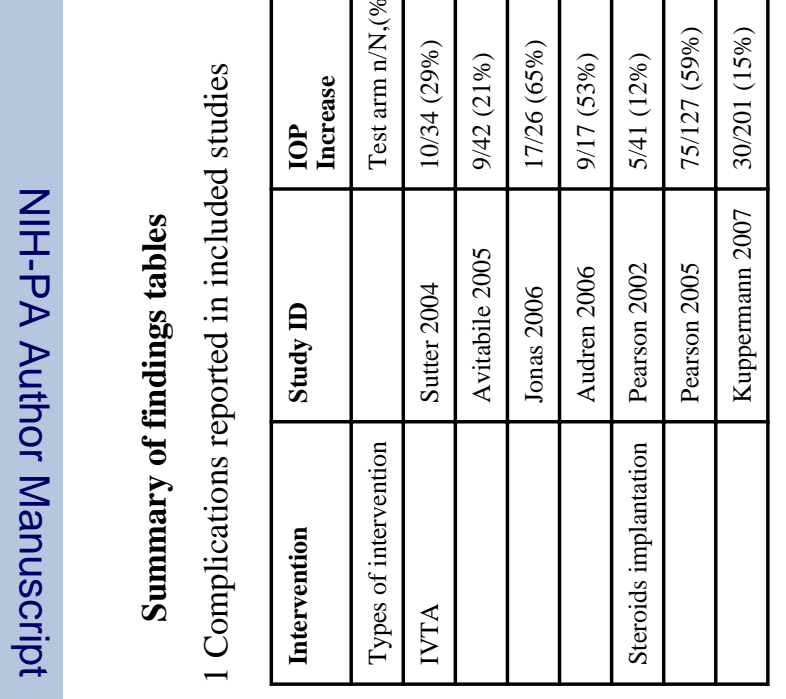




\section{Characteristics of studies}

\section{Characteristics of included studies}

\begin{tabular}{|c|c|c|}
\hline \multicolumn{3}{|l|}{ Audren 2006} \\
\hline Methods & \multicolumn{2}{|c|}{$\begin{array}{l}\text { Study design: RCT ( } 4 \text { patients with asymmetrical diffuse DME were not randomized). } \\
\text { Method of randomization: Randomization sequence was generated from a random number table and was block- } \\
\text { randomized into groups of } 4 \text {. } \\
\text { Number randomized: For patients with symmetrical diffuse DME ( } 13 \text { patients, } 26 \text { eyes), one eye was randomized } \\
\text { to IVTA ( } 13 \text { eyes), and the fellow eye served as a control ( } 13 \text { eyes). } \\
\text { Method of allocation concealment: Not reported. } \\
\text { Outcome assessor masking: Unclear. } \\
\text { Losses to follow up: No losses to follow up at } 6 \text { months. } \\
\text { Intention-to-treat analysis: Not performed. }\end{array}$} \\
\hline Participants & \multicolumn{2}{|c|}{$\begin{array}{l}\text { Inclusion criteria: Bilateral diffuse DME which was unresponsive to adequate laser photocoagulation, with no sign } \\
\text { of vitreomacular traction on either biomicroscopy or OCT examination; CMT }>380 \text { um on OCT in both eyes; } \\
\text { glycated haemoglobin }(\mathrm{HbA} 1 \mathrm{c})<9.5 \% \text {, systolic blood pressure }<150 \mathrm{~mm} \mathrm{Hg} \text {, and diastolic blood pressure }<90 \\
\text { mmHg. } \\
\text { Exclusion criteria: Glaucoma, ocular hypertension and corticosteroid-induced ocular hypertension. } \\
\text { Types of DME: diffuse macular edema. } \\
\text { Prior laser treatment: Yes. } \\
\text { Age: } 60.1 \pm 9.0 \text { (included four non-randomized patients). } \\
\text { Comparability of baseline characteristics: We can not assess the comparability of baseline characteristics because } \\
\text { the baseline data presented in the paper consisted of both randomized and non-randomized patients. }\end{array}$} \\
\hline Interventions & \multicolumn{2}{|c|}{$\begin{array}{l}\text { Test intervention: IVTA }(4 \mathrm{mg}) \text {. } \\
\text { Control intervention: No treatment. } \\
\text { Repeat IVTA treatment: Not reported. }\end{array}$} \\
\hline Outcomes & \multicolumn{2}{|c|}{$\begin{array}{l}\text { Primary outcome: Change in CMT at } 4,12 \text { and } 24 \text { weeks follow-up. } \\
\text { Measurement of primary outcome: CMT was defined by the average thickness of a central macular region } 1000 \mathrm{um} \\
\text { in diameter, centered on the patient's foveola, and measured using OCT } 2 \text { and A5 mapping software. } \\
\text { Secondary outcomes: Change in visual acuity relative to pre-injection level; IOP; and cataract progression. } \\
\text { Measurement of secondary outcomes: Visual acuity was measured using ETDRS procedure; IOP was measured by } \\
\text { Goldmann applanation tonometry; measurement for cataract progression was not reported. }\end{array}$} \\
\hline Notes & \multicolumn{2}{|c|}{$\begin{array}{l}\text { Data source: Published data. } \\
\text { Funding souce: Non-industry funded. } \\
\text { Country: France. } \\
\text { Others: Data could not be used in meta-analysis because 1) the results reported were not stratified by study design } \\
\text { (randomized versus non-randomized eyes); 2) the correlation between paired eyes within a participant was not } \\
\text { accounted for. }\end{array}$} \\
\hline \multicolumn{3}{|l|}{ Risk of bias table } \\
\hline Item & Authors' judgement & Support for judgement \\
\hline Allocation concealment? & Unclear & B - Unclear \\
\hline \multicolumn{3}{|l|}{ Avitabile 2005} \\
\hline Methods & \multicolumn{2}{|c|}{$\begin{array}{l}\text { Study design: RCT. } \\
\text { Method of randomization: Computer-generated pseudorandom numbers of variable block size was used. } \\
\text { Number randomized: } 48 \text { DME eyes ( } 17 \text { eyes to IVTA arm, } 16 \text { eyes to MLG arm and } 15 \text { eyes to IVTA with MLG } \\
\text { arm). } \\
\text { Method of allocation concealment: Sealed opaque envelopes, each serially numbered, containing the treatment } \\
\text { codes were prepared before the study began by an administrative clerk otherwise not involved in the study and } \\
\text { guarded in a locked cabinet of the Institute. } \\
\text { Outcome assessor masking: Adequately masked. } \\
\text { Losses to follow up: No losses to follow up at } 6 \text { months; } 5 / 17 \text { (29\%) eyes in the IVTA arm and } 6 / 16(38 \%) \text { eyes in } \\
\text { the MLG arm at } 9 \text { months of follow up. } \\
\text { Intention-to-treat analysis: Performed. }\end{array}$} \\
\hline Participants & \multicolumn{2}{|c|}{$\begin{array}{l}\text { Inclusion criteria: Older than } 55, \mathrm{ME} \text { (DME, CRVO or BRVO) lasting at least } 5 \text { months, had VA }<=20 / 50 \text {, } \\
\text { refraction below } \pm 3 \text { diopters. } \\
\text { Exclusion criteria: Ocular trauma, inflammation, recent surgery, glaucoma or ocular hypertension, poorly } \\
\text { controlled diabetes, hypertension, nephropathy, and macular ischemia. } \\
\text { Types of DME: CME. } \\
\text { Prior laser treatment: None. } \\
\text { Age: } 64 \pm 5 \\
\text { Comparability of baseline characteristics: Baseline visual acuity was comparable in general. Baseline retinal } \\
\text { thickness was } 535 \pm 101 \text { um in IVTA arm and } 601 \pm 88 \text { um in MLG arm. }\end{array}$} \\
\hline Interventions & \multicolumn{2}{|c|}{ Test intervention: IVTA (4 mg). } \\
\hline
\end{tabular}

Cochrane Database Syst Rev. Author manuscript; available in PMC 2013 October 21. 


\begin{tabular}{|c|c|c|}
\hline & \multicolumn{2}{|c|}{$\begin{array}{l}\text { Control intervention 1: MLG. } \\
\text { Control intervention 2: IVTA with MLG. } \\
\text { Repeat IVTA treatment: Allowed. }\end{array}$} \\
\hline Outcomes & \multicolumn{2}{|c|}{$\begin{array}{l}\text { Primary outcome: Best-corrected VA and CMT at } 45 \text { days, } 3,6 \text { and } 9 \text { months follow-up. } \\
\text { Measurement of primary outcome: VA by ETDRS chart; CMT by OCT. } \\
\text { Secondary outcomes: Complication rate, including IOP }>21 \text { mmHg, cataract progression, or injection-related } \\
\text { complications. } \\
\text { Measurement of secondary outcomes: IOP was measured by applanation tonometer; cataract progression was } \\
\text { determined according to Lens Opacities Classification System III grading; patients were monitored for potential } \\
\text { injection-related complications (retinal detachment, vitreous hemorrhage, and endophthalmitis). }\end{array}$} \\
\hline Notes & \multicolumn{2}{|c|}{$\begin{array}{l}\text { Data source: Published data. } \\
\text { Funding souce: Non-industry funded. } \\
\text { Country: Italy. } \\
\text { Others: Only data from DME eyes were used in this review. }\end{array}$} \\
\hline \multicolumn{3}{|l|}{ Risk of bias table } \\
\hline Item & Authors' judgement & Support for judgement \\
\hline Allocation concealment? & Yes & A - Adequate \\
\hline \multicolumn{3}{|l|}{ Jonas 2006} \\
\hline Methods & \multicolumn{2}{|c|}{$\begin{array}{l}\text { Study design: RCT. } \\
\text { Method of randomization: Not reported. } \\
\text { Number randomized: } 40 \text { eyes of } 38 \text { patients were randomized at 2:1 ratio into IVTA arm ( } 28 \text { eyes) and shame } \\
\text { procedure arm ( } 12 \text { eyes). } \\
\text { Method of allocation concealment: Not reported. } \\
\text { Outcome assessor masking: Unclear. } \\
\text { Losses to follow up: } 5 / 28 \text { (18\%) eyes in the IVTA arm and 3/12 (25\%) eyes in the shame procedure arm at } 6 \\
\text { months of follow up. } \\
\text { Intention-to-treat analysis: Not performed. }\end{array}$} \\
\hline Participants & \multicolumn{2}{|c|}{$\begin{array}{l}\text { Inclusion criteria: Diffuse DME as defined by ETDRS involving the central fovea and persisting for at least } 3 \\
\text { months. Laser treatment had been performed, if indicated, according to the ETDRS guidelines at least } 3 \text { months } \\
\text { prior to inclusion. All patients had refractory macular edema. All patients were observed to have good metabolic } \\
\text { control. } \\
\text { Exclusion criteria: Uncontrolled glaucoma, loss of vision as result of other causes, systemic treatment with } \\
\text { prednisolone, severe systemic disease, or any condition affecting follow-up or documentation. } \\
\text { Types of DME: Diffuse DME involving central fovea. } \\
\text { Age: IVTA: } 65.7 \pm 7.5 ; \text { Placebo: } 68.8 \pm 9.9 \text {. } \\
\text { Comparability of baseline characteristics: Baseline VA and IOP were comparable. }\end{array}$} \\
\hline Interventions & \multicolumn{2}{|c|}{$\begin{array}{l}\text { Test intervention: IVTA }(20 \mathrm{mg}) \text {. } \\
\text { Control intervention: Shame procedure (sterile cotton tip placed onto conjunctiva). } \\
\text { Repeat IVTA treatment: Not allowed. }\end{array}$} \\
\hline Outcomes & \multicolumn{2}{|c|}{$\begin{array}{l}\text { Primary outcome: Proportion of improvement of best-corrected } \log \text { MAR visual acuity by } 2 \text { or more lines and } 3 \text { or } \\
\text { more lines at } 6 \text { months follow-up. } \\
\text { Measurement of primary outcome: Not reported. } \\
\text { Secondary outcomes: Any change in visual acuity compared with the pre-injection level. } \\
\text { Measurement of secondary outcomes: Not reported. }\end{array}$} \\
\hline Notes & \multicolumn{2}{|c|}{$\begin{array}{l}\text { Data source: Published data. } \\
\text { Funding souce: Non-industry funded. } \\
\text { Country: Germany. }\end{array}$} \\
\hline \multicolumn{3}{|l|}{ Risk of bias table } \\
\hline Item & Authors' judgement & Support for judgement \\
\hline Allocation concealment? & Unclear & B - Unclear \\
\hline \multicolumn{3}{|l|}{ Kuppermann 2007} \\
\hline Methods & \multicolumn{2}{|c|}{$\begin{array}{l}\text { Study design: RCT. } \\
\text { Method of randomization: One eye per patient was randomized with a 1:1:1 allocation to observation or treatment } \\
\text { with dexamethasone DDS, } 350 \text { or } 700 \text { ug. Randomization was performed centrally and was stratified by underlying } \\
\text { cause of macular edema. } \\
\text { Number randomized: } 315 \text { eyes were randomized ( } 105 \text { eyes into each arm), among which } 172 \text { eyes were diagnosed } \\
\text { with DME ( } 58 \text { eyes in dexamethasone DDS } 350 \mathrm{ug} \text { arm, } 57 \text { eyes in the dexamethasone DDS } 700 \text { ug arm, and } 57 \\
\text { eyes in the observation arm). } \\
\text { Method of allocation concealment: Not reported. } \\
\text { Outcome assessor masking: Fluorescein angiograms were read by masked graders; not reported for other outcomes. }\end{array}$} \\
\hline
\end{tabular}




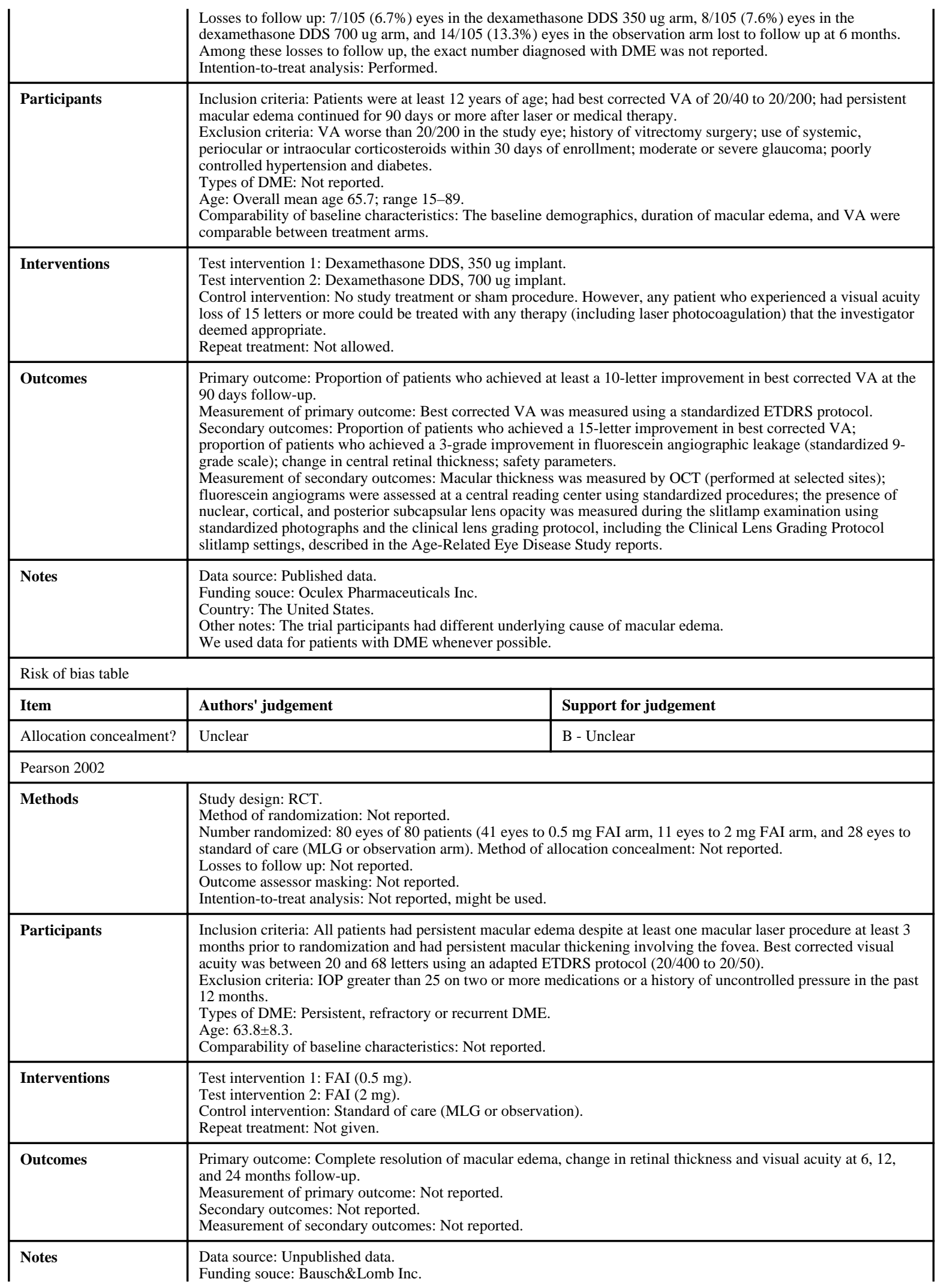




\begin{tabular}{|c|c|c|}
\hline & \multicolumn{2}{|c|}{$\begin{array}{l}\text { Country: The United States. } \\
\text { Others: Data from FAI }(2 \mathrm{mg}) \text { arm were not reported. }\end{array}$} \\
\hline \multicolumn{3}{|l|}{ Risk of bias table } \\
\hline Item & Authors' judgement & Support for judgement \\
\hline Allocation concealment? & Unclear & B - Unclear \\
\hline \multicolumn{3}{|l|}{ Pearson 2005} \\
\hline Methods & \multicolumn{2}{|c|}{$\begin{array}{l}\text { Study design: RCT. } \\
\text { Method of randomization: Not reported. } \\
\text { Number randomized: } 197 \text { eyes of } 197 \text { patients were randomized at 2:1 ratio into FAI arm (127 eyes) and standard } \\
\text { of care arm ( } 70 \text { eyes). } \\
\text { Method of allocation concealment: Not reported. } \\
\text { Outcome assessor masking: Not reported. } \\
\text { Losses to follow up: Not reported. } \\
\text { Intention-to-treat analysis: Not reported, might be used. }\end{array}$} \\
\hline Participants & \multicolumn{2}{|c|}{$\begin{array}{l}\text { Inclusion criteria: Not reported. } \\
\text { Exclusion criteria: Not reported. } \\
\text { Types of DME: Not reported. } \\
\text { Age: } 62.2 \pm 10.1 \text {. } \\
\text { Comparability of baseline characteristics: Not reported. }\end{array}$} \\
\hline Interventions & \multicolumn{2}{|c|}{$\begin{array}{l}\text { Test intervention: FAI }(0.59 \mathrm{mg}) \text {. } \\
\text { Control intervention: Standard of care (MLG or observation). } \\
\text { Repeat treatment: Not reported. }\end{array}$} \\
\hline Outcomes & \multicolumn{2}{|c|}{$\begin{array}{l}\text { Primary outcome: Change in visual acuity, retinal thickness and Diabetic Retinopathy Severity Score, resolution of } \\
\text { retinal thickening at 12, } 24 \text { and } 36 \text { months. } \\
\text { Measurement of primary outcome: Not reported. } \\
\text { Secondary outcomes: Not reported. } \\
\text { Measurement of secondary outcomes: Not reported. }\end{array}$} \\
\hline Notes & \multicolumn{2}{|c|}{$\begin{array}{l}\text { Data source: Unpublished data. } \\
\text { Funding souce: Bausch\&Lomb Inc. } \\
\text { Country: The United States. }\end{array}$} \\
\hline \multicolumn{3}{|l|}{ Risk of bias table } \\
\hline Item & Authors' judgement & Support for judgement \\
\hline Allocation concealment? & Unclear & B - Unclear \\
\hline \multicolumn{3}{|l|}{ Sutter 2004} \\
\hline Methods & \multicolumn{2}{|c|}{$\begin{array}{l}\text { Study design: RCT. } \\
\text { Method of randomization: Computer-generated pseudorandom numbers of variable block size was used. } \\
\text { Number randomized: } 69 \text { eyes of } 43 \text { patients ( } 34 \text { eyes into IVTA arm and } 35 \text { eyes into shame treatment arm). } \\
\text { Method of allocation concealment: Sealed opaque envelopes, each serially numbered, were prepared by an } \\
\text { administrative clerk otherwise not involved in the study and were kept in a locked drawer in the clinic. } \\
\text { Outcome assessor masking: Adequately masked. } \\
\text { Losses to follow up: } 1 / 34 \text { (3\%) eyes in the IVTA arm and } 3 / 35 \text { (9\%) eyes in the placebo arm at } 3 \text { months of follow } \\
\text { up; } 3 / 34 \text { (9\%) eyes in the IVTA arm and } 6 / 35 \text { (17\%) eyes in the placebo arm at } 24 \text { months of follow up. } \\
\text { Intention-to-treat analysis: Performed at } 24 \text { months report. }\end{array}$} \\
\hline Participants & \multicolumn{2}{|c|}{$\begin{array}{l}\text { Inclusion criteria: Patients with persistent DME, diffuse or focal, involving the central fovea persisting } 3 \text { months or } \\
\text { more after adequate laser treatment and best-corrected VA in the affected eye(s) of } 6 / 9 \text { or worse. } \\
\text { Exclusion criteria: Uncontrolled glaucoma, loss of vision as a result of other causes, systemic treatment with more } \\
\text { than } 5 \mathrm{mg} \text { prednisolone (or equivalent) daily, intercurrent severe systemic disease, or any condition affecting } \\
\text { follow-up or documentation. } \\
\text { Types of DME: Persistent DME, diffuse or focal, involving central fovea. } \\
\text { Age: Mean } 64 \text {. } \\
\text { Comparability of baseline characteristics: Baseline VA, retinal thickness and IOP were comparable between two } \\
\text { treatment arms. }\end{array}$} \\
\hline Interventions & \multicolumn{2}{|c|}{$\begin{array}{l}\text { Test intervention: IVTA }(4 \mathrm{mg}) \text {. } \\
\text { Control intervention: Shame treatment (subconjunctival saline injection). } \\
\text { Repeat IVTA treatment: Allowed. }\end{array}$} \\
\hline Outcomes & \multicolumn{2}{|c|}{$\begin{array}{l}\text { Primary outcome: Percentage of eyes in which best-corrected logMAR visual acuity improved by } 5 \text { or more letters } \\
\text { at } 2 \text { years and percentage of eyes with moderate or severe adverse events. } \\
\text { Measurement of primary outcome: VA was measured using ETDRS charts with standardized procedures. } \\
\text { Secondary outcomes: Change in visual acuity relative to preinjection level; change in macular thickness. } \\
\text { Measurement of secondary outcomes: Macular thickness was measured by OCT. }\end{array}$} \\
\hline
\end{tabular}




\begin{tabular}{|l|l|l|} 
Notes & $\begin{array}{l}\text { Data source: Published data. } \\
\text { Funding souce: Non-industry funded. } \\
\text { Country: Australia. }\end{array}$ \\
\hline Risk of bias table & Authors' judgement & Support for judgement \\
\hline Item & A - Adequate \\
\hline Allocation concealment? & Yes &
\end{tabular}

BRVO: branch retinal vein occlusion

CME: cystoid macular edema

CMT: central macular thickness

CRVO: central retinal vein occlusion

DDS: drug delivery system

DME: diabetic macular edema

ETDRS: Early Treatment Diabetic Retinopath Study

FAI: fluocinolone acetonide implant

IOP: intraocular pressure

IVTA: intravitreal triamcinalone acetate injection

MLG: macular laser grid photocoagulation

OCT: optical coherence tomography

RCT: randomized controlled trial

VA: visual acuity 


\section{Characteristics of excluded studies}

\begin{tabular}{|c|c|}
\hline \multicolumn{2}{|l|}{ Bandello 2004} \\
\hline Reason for exclusion & $\begin{array}{l}\text { Comparison intervention did not meet inclusion criteria: Intravitreal injection was compared to intravitreal injection } \\
\text { plus grid-laser photocoagulation treatment. }\end{array}$ \\
\hline \multicolumn{2}{|l|}{ Bonini-Filho 2005} \\
\hline Reason for exclusion & $\begin{array}{l}\text { Comparison intervention did not meet inclusion criteria: Intravitreal injection was compared with sub-Tenon's } \\
\text { infusion of tramcinolone acetonide. The same drug was used but with different means of administration. }\end{array}$ \\
\hline \multicolumn{2}{|l|}{ Cardillo 2005} \\
\hline Reason for exclusion & $\begin{array}{l}\text { Comparison intervention did not meet inclusion criteria: Intravitreal injection was compared with sub-Tenon's } \\
\text { injection of tramcinolone acetonide. The same drug was used but with different places of administration. }\end{array}$ \\
\hline \multicolumn{2}{|l|}{ Er 2005} \\
\hline Reason for exclusion & $\begin{array}{l}\text { Not a RCT: } 30 \text { patients with diffuse DME were treated by IVTA and were compared to a retrospective control group } \\
\text { who had received MLG. }\end{array}$ \\
\hline \multicolumn{2}{|l|}{ Jonas 2004} \\
\hline Reason for exclusion & $\begin{array}{l}\text { Not a RCT: Only the eye with lower baseline visual acuity or with the more marked macular edema received } \\
\text { intervention. The contralateral eyes served as control. }\end{array}$ \\
\hline \multicolumn{2}{|l|}{ Spandau 2005} \\
\hline Reason for exclusion & Comparison intervention did not meet inclusion criteria: Dosage dependence study of IVTA. \\
\hline \multicolumn{2}{|l|}{ Verma 2004} \\
\hline Reason for exclusion & $\begin{array}{l}\text { Test intervention did not meet inclusion criteria: Posterior sub-Tenon triamcinolone was compared with grid laser } \\
\text { photocoagulation. }\end{array}$ \\
\hline
\end{tabular}

DME: diabetic macular edema

IVTA: intravitreal triamcinalone acetate injection

MLG: macular laser grid photocoagulation

RCT: randomized controlled trial 


\section{Characteristics of ongoing studies}

\begin{tabular}{|c|c|}
\hline \multicolumn{2}{|l|}{ Ip 2004} \\
\hline Study name & A randomized trial comparing intravitreal triamcinolone acetonide and laser photocoagulation for DME. \\
\hline \multicolumn{2}{|l|}{ Methods } \\
\hline Participants & $\begin{array}{l}\text { Patients } 18 \text { years of age and older with diabetes mellitus and macular edema in one or both eyes may be eligible for } \\
\text { this study. }\end{array}$ \\
\hline Interventions & $\begin{array}{l}\text { 1) Intravitreal injection of } 1 \mathrm{mg} \text { of triamcinolone acetonide; 2) Intravitreal injection of } 4 \mathrm{mg} \text { of triamcinolone } \\
\text { acetonide; 3) standard of care group: conventional treatment consisting of focal/grid photocoagulation. }\end{array}$ \\
\hline Outcomes & $\begin{array}{l}\text { Primary: Visual acuity (measured with Electronic-ETDRS) } \\
\text { Secondary: Retinal thickening (measured on OCT). }\end{array}$ \\
\hline Starting date & June 2004 \\
\hline Contact information & $\begin{array}{l}\text { Michael Ip, MD } \\
\text { University of Wisconsin Medical School } \\
\text { Fundus Photograph Reading Center } \\
\text { Park West One } 406 \text { Science Drive, Suite } 400 \\
\text { Madison, WI } 53711 \\
\text { msip@ facstaff.wisc.edu } \\
\text { Phone: 608-263-5749 } \\
\text { Fax: 608-263-0525 }\end{array}$ \\
\hline Notes & $\begin{array}{l}\text { Primary outcome at } 3 \text { years (preliminary outcome assessment at } 1 \text { year) } \\
\text { Planned sample size: } 795 \text { patients. }\end{array}$ \\
\hline
\end{tabular}

DME: diabetic macular edema

ETDRS: Early Treatment Diabetic Retinopath Study

OCT: optical coherence tomography 